\title{
Taurine conjugates in the lipid fraction of Euglena cells and their mitochondria
}

\author{
TekChand Saidha, Arthur I. Stern $\dagger$ and Jerome A. SchifF* \\ Photobiology Group, Biology Department Brandeis University, Waltham, MA 02254, USA
}

(Received 6 May 1992; revised 4 August 1992; accepted 23 September 1992)

\begin{abstract}
Dark-grown resting (non-dividing) cells of Euglena gracilis var. bacillaris and mutants $\mathrm{W}_{3} \mathrm{BUL}$ (with a proplastid remnant) and $\mathrm{W}_{10} \mathrm{BSmL}$ (lacking plastids) incubated with ${ }^{35} \mathrm{SO}_{4}^{2-}$ form a series of labelled lipids which are low or absent in dividing cells. These lipids all release labelled taurine on mild acid-hydrolysis. Treatment of the labelled lipids with 2,4-dinitrofluorobenzene (DNFB) followed by acid hydrolysis does not yield labelled dinitrophenyltaurine (DNP-taurine), but treatment with DNFB after hydrolysis readily forms labelled DNP-taurine, indicating that taurine is linked to the lipids by at least the amino group. Illumination increases the labelling of these taurolipids in plastid-containing cells (wild-type and $W_{3} B U L$ ) but has little effect in cells lacking plastids $\left(W_{10} B S m L\right)$; labelling is highest in $W_{10}$ cells irrespective of illumination. This indicates that the presence of a plastid may exert a negative control on taurolipid formation which is relieved by light. The same series of labelled lipids is found in isolated purified mitochondria from mutant $W_{10}$, indicating that this organelle is a site for taurolipid deposition. The formation of taurolipids under non-dividing conditions may be a response to nutritional stress and these negatively charged constituents (as well as the thylakoid sulpholipid) may serve to protect membranes by repelling deleterious negatively charged oxygen species.
\end{abstract}

\section{Introduction}

Lipid extracts of cells of Euglena gracilis var. bacillaris grown in darkness or light on a complete medium with ${ }^{35} \mathrm{SO}_{4}^{2-}$ show a single major labelled spot on thin-layer silica gel chromatography corresponding to the thylakoid sulpholipid (diacylsulphoquinovosylglycerol); much higher labelling is observed in the light than in the dark (Saidha \& Schiff, 1989). Mutant $\mathrm{W}_{3} \mathrm{BUL}\left(\mathrm{W}_{3}\right)$ retains only a proplastid remnant but also shows light-stimulated accumulation of the sulpholipid under dividing conditions. $W_{3}$ yields a chromatographic pattern much like the wild-type with a single major spot corresponding to the sulpholipid (Saidha \& Schiff, 1989). Dividing cells of mutant $\mathrm{W}_{10} \mathrm{BSmL}\left(\mathrm{W}_{10}\right)$ lack plastids completely (Osafune \& Schiff, 1983) and show no major radioactive spot under the same conditions in either light or

*Author for correspondence. Tel. (617) 7362685 ; fax (617) 736 2689.

$\dagger$ Permanent address: Botany Department, University of Massachusetts, Amherst, MA 01003, USA.

Abbreviations: DNFB, 2,4-dinitrofluorobenzene; DNP-taurine, dinitrophenyltaurine. darkness. $\mathrm{W}_{10}$, therefore, does not make the sulpholipid (Saidha \& Schiff, 1989). Although traces of other radioactive spots could occasionally be seen on these chromatograms, their nature only became apparent in a study of resting (non-dividing) cells of Euglena incubated with ${ }^{35} \mathrm{SO}_{4}^{2-}$ on a medium containing mannitol (not utilized as a carbon source for growth by Euglena), $\mathrm{MgCl}_{2}$ and $\mathrm{KH}_{2} \mathrm{PO}_{4}$. Under non-dividing conditions, cells of wild-type Euglena and $\mathrm{W}_{3}$ incubated with ${ }^{35} \mathrm{SO}_{4}^{2-}$ still form radioactive sulpholipid. In addition, wild-type, $\mathrm{W}_{3}$ and $\mathrm{W}_{10}$ accumulate substantial radioactivity in several spots that were only labelled slightly in dividing cells. As we will show in this paper, these spots contain taurine conjugates of lipids ('taurolipids'). The properties and labelling of these compounds in resting cells of Euglena wild-type, $\mathrm{W}_{3}$ and $\mathrm{W}_{10}$ will be presented and their possible physiological function will be discussed. A brief abstract of this work has appeared (Saidha et al., 1990).

\section{Methods}

Cell culture and labelling. Euglena gracilis Klebs var. bacillaris Cori and mutants $\mathrm{W}_{3}$ and $\mathrm{W}_{10}$ were grown in darkness with shaking at $26^{\circ} \mathrm{C}$ on modified Hutner's pH 3.5 medium (MHM) containing low vitamin 
$\mathbf{B}_{12}\left(50 \mathrm{ng} \mathrm{l}^{-1}\right)$ and just enough sulphate to allow normal growth as described previously (Saidha et al., 1988; Cogburn \& Schiff, 1984). After at least three transfers in darkness, the cells were grown in darkness for $4 \mathrm{~d}$. Either these cells were used directly, or they were diluted with resting medium (Stern et al., 1964) containing $0.045 \mathrm{M}-$ mannitol (an osmoticum not used as a carbon source), $0.01 \mathrm{M}-\mathrm{MgCl}_{2}$

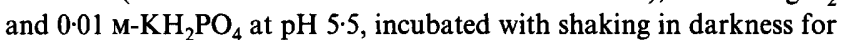
$72 \mathrm{~h}$ (during which time cell division ceases) and then used for experiments in which resting (non-dividing) cells were required. Cells were counted in a Coulter model A counter as previously described (Zeldin \& Schiff, 1967). All manipulations of dark-grown cells were done under dim green safelights (Schiff, 1972).

For labelling experiments, carrier-free ${ }^{35} \mathrm{SO}_{4}^{2-}[0.5 \mathrm{mCi}(18.5 \mathrm{MBq})$ in $250 \mathrm{ml}$ ] was added to growing or resting cultures. The cultures were then shaken in darkness or in light $\left[90 \mathrm{ft}-\mathrm{c}\left(3.08 \mathrm{~W} \mathrm{~m}^{-2}\right)\right.$ from white and red fluorescent lamps] and $50 \mathrm{ml}$ samples were removed at the indicated times. The culture sample was passed through four layers of cheesecloth and was then centrifuged at $370 \mathrm{~g}$ for $5 \mathrm{~min}$. The cell pellet received $5 \mathrm{ml}$ of chloroform/methanol $(2: 1, \mathrm{v} / \mathrm{v})$ and was then incubated at $37^{\circ} \mathrm{C}$ for $20 \mathrm{~min}$. A volume of $0.45 \%(\mathrm{w} / \mathrm{v}) \mathrm{NaCl}$ solution equal to 0.25 of the volume of the solvent/cell mixture was then added and mixed thoroughly by vortexing; the mixture was then centrifuged at $370 \mathrm{~g}$ for $5 \mathrm{~min}$. The lower organic phase was removed and taken to dryness in a stream of $\mathrm{N}_{2}$ (Haas et al., 1980).

Preparation of mitochondria from ${ }^{35} S$-labelled $W_{10} B S m L$ cells. In previous work we have described methods for preparation of clean, coupled mitochondria from Euglena using a Yeda press to break the cells. Since then, others have used sonication to break the cells which yields equally good coupled mitochondria (Moreno-Sanchez \& Raya, 1987). The sonication method proved to be most convenient for breaking radioactive cells in the present work and this was combined with our previous methods for isolating and purifying the mitochondria (Gomez-Silva et al., 1985; Saidha et al. 1985). The total procedure is as follows. A culture of Euglena $\left(1.44-1.58 \times 10^{8}\right.$ cells in $350 \mathrm{ml}$ representing $1.75 \mathrm{~g}$ wet wt of cells) received carrier-free ${ }^{35} \mathrm{SO}_{4}^{2-}$ and was incubated for $72 \mathrm{~h}$ in darkness under resting conditions as described above. The culture was then centrifuged at $370 \mathrm{~g}$ for $5 \mathrm{~min}$ and the pellet was washed twice with $100 \mathrm{ml}$ of Buffer A (containing $25 \mathrm{~mm}-\mathrm{HEPES} / \mathrm{KOH}$ buffer, pH 7.4, 0.25 M-sucrose and $0.005 \mathrm{M}$-EDTA) by centrifugation. The pellet obtained after the second wash was resuspended in $25 \mathrm{ml}$ of Buffer A and sonicated continuously at $70 \%$ of maximum power for two intervals of $15 \mathrm{~s}$ each in an ice-bath using a Branson model 200 sonifier with a microtip $0.4 \mathrm{~cm}$ in diameter. After sonication, the suspension was centrifuged at $370 \mathrm{~g}$ for $5 \mathrm{~min}$ and the pellet was discarded. The supernatant fraction was then centrifuged at $10000 \mathrm{~g}$ for $10 \mathrm{~min}$ to obtain the crude mitochondrial pellet. This pellet was resuspended in 1-2 $\mathrm{ml}$ of Buffer $A$ and $0.5-1.0 \mathrm{ml}$ was layered on top of a discontinuous Percoll density gradient (consisting of steps of 60,30 , 20,10 and $5 \%, \mathrm{w} / \mathrm{v}$, Percoll) described in detail previously (Saidha $e t$ al., 1985). Band A, appearing at the interface of $60 \%$ and $30 \%$ Percoll after centrifugation and containing highly purified and intact mitochondria (Gomez-Silva et al., 1985) was collected by suction, diluted with $20 \mathrm{ml}$ of Buffer A and the mixture was centrifuged at $10000 \mathrm{~g}$ for $10 \mathrm{~min}$ to remove Percoll. The pellet of the purified mitochondria thus obtained was extracted for lipids as described above for cells. Separation of the lipids was achieved by TLC as described below.

Separation and purification of ${ }^{35} \mathrm{~S}$-labelled lipids. The dried organic phase was resuspended in $200 \mu \mathrm{l}$ of chloroform/methanol $(2: 1, \mathrm{v} / \mathrm{v})$ and either spotted (for quantitative work) or strip-loaded (for preparative work) onto a glass silica gel thin-layer chromatographic (TLC) plate, $20 \times 20 \mathrm{~cm}$, previously activated by heating at $100^{\circ} \mathrm{C}$ for $1 \mathrm{~h}$. The plate was developed in chloroform/methanol/acetic acid/ water $(65: 35: 8: 4$, by vol.). After development, the dried TLC plate was exposed to $\mathrm{X}$-ray film and radioactive areas corresponding to the lipids were scraped from the plate and counted in a scintillation counter (Saidha et al., 1985) for quantitative analysis; for preparative work, the strip was scraped and re-extracted with chloroform/methanol and repartitioned with $\mathrm{NaCl}$ as described above.

Acid hydrolysis of the unknown ${ }^{35}$ S-labelled lipids. Measured samples of TLC-purified lipids in chloroform/methanol were taken to dryness. $\mathrm{HCl}$ and Triton $\mathrm{X}-100$ were added to each sample to yield final concentrations of $1 \mathrm{~m}$ and $0.1 \%$ respectively (Benson et al., 1959). The mixtures were heated at $100^{\circ} \mathrm{C}$ for $30 \mathrm{~min}$, dried under $\mathrm{N}_{2}$ and the residual $\mathrm{HCl}$ removed under vacuum overnight in a desiccator over $\mathrm{NaOH}$. The compounds in the hydrolysate were separated by paper electrophoresis in sodium borate $(\mathrm{pH} 8.0)$, sodium citrate $(\mathrm{pH} \mathrm{5.8)}$ and formic/acetic acid (pH 2.0) buffer systems (Saidha et al., 1988). Known compounds including taurine and dinitrophenyl taurine (DNPtaurine) were examined for co-electrophoresis with the ${ }^{35} \mathrm{~S}$-labelled hydrolysed products by autoradiography. Co-chromatography of the products with taurine was also investigated on cellulose thin-layers in butanol/acetic acid/water ( $80: 20: 20$, by vol.), propan-2-ol/ammonia/ water (6:3:1, by vol.), and two-dimensionally in methanol/n-butanol/ benzene/water $(120: 60: 60: 60$, by vol.) followed by n-butanol/acetic acid/water (100:22:50, by vol.) (Schiff, 1959). Co-chromatography of DNP-taurine was investigated in the two-dimensional system and in the butanol/acetic acid/water and propan-2-ol/ammonia/water systems described above, and on cellulose thin-layers in chloroform/ methanol/acetic acid/water $(65: 35: 8: 4$, by vol. $)$.

Other methods. DNP-taurine was synthesized from taurine using 2,4dinitrofluorobenzene (DNFB) by the method of Pentz et al. (1957) scaled down 10 -fold. DNP-derivatization of the ${ }^{35} \mathrm{~S}$-labelled acidhydrolysed products of the unknown lipids was achieved by substituting the neutralized acid-hydrolysed products for taurine in the above procedure and using the reaction mixture without further purification for electrophoresis or chromatography. Taurine was visualized by ninhydrin spray (Saidha et al., 1988). DNP-taurine was located by its yellow colour.

\section{Results and Discussion}

Resting cells of Euglena gracilis var. bacillaris and mutants $\mathrm{W}_{3}$ and $\mathrm{W}_{10}$ incubated in light or darkness with ${ }^{35} \mathrm{SO}_{4}^{2-}$ accumulate at least three novel chloroform/ methanol-extractable ${ }^{35} \mathrm{~S}$-labelled compounds, which separate during chromatography on silica gel thin-layer plates. These are designated A, B and C in Fig. 1. Labelled sulpholipid is also found in all cells except those of $\mathrm{W}_{10}$ (Saidha \& Schiff, 1989) which lack plastids completely (Osafune \& Schiff, 1983).

In general, compounds $\mathrm{A}, \mathrm{B}$ and $\mathrm{C}$ are highly labelled in light or darkness under these conditions (Table 1). In wild-type and $\mathrm{W}_{3}$ light stimulates the labelling of $\mathrm{A}, \mathrm{B}$ and $\mathrm{C}$, but in $\mathrm{W}_{10}$ light has a comparatively small effect and is stimulatory to labelling of compound $\mathrm{A}$, has no effect on labelling of compound B and is somewhat inhibitory to labelling of compound $C$. However, $W_{10}$ generally shows the highest labelling of the compounds compared with wild-type and $\mathrm{W}_{3}$. The data suggest that the presence of a plastid (a proplastid or chloroplast in dark-grown or light-grown wild-type cells or a proplastid remnant in dark-grown or light-grown $\mathrm{W}_{3}$ ) brings the system under negative control, since $\mathrm{W}_{10}$, which lacks 


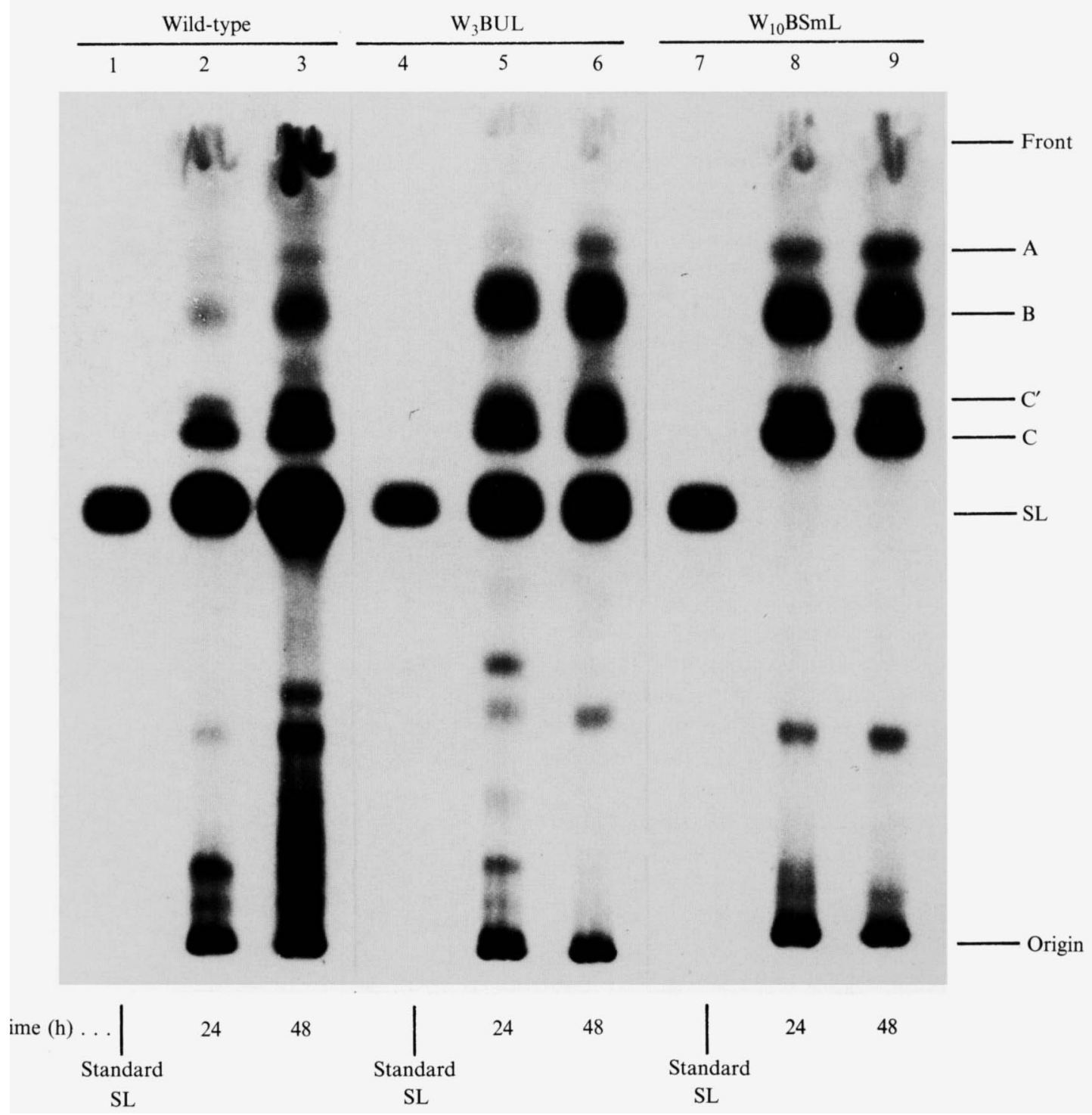

Fig. 1. Autoradiograms of thin-layer silica gel plates developed in chloroform/methanol/acetic acid/water $(65: 35: 8: 4$, by vol.) showing separation of ${ }^{35} \mathrm{~S}$-labelled lipids from dark-grown resting wild-type (lanes 2 and 3 ) cells of Euglena gracilis var. bacillaris and mutants $\mathrm{W}_{3}$ (lanes 5 and 6) and $\mathrm{W}_{10}$ (lanes 8 and 9) incubated with carrier-free ${ }^{35} \mathrm{SO}_{4}^{2-}$ in the light for the indicated times. Lanes 1 , 4 and 7 received $\left[{ }^{35}\right.$ S]sulpholipid standard prepared from light-grown wild-type Euglena as described previously (Saidha \& Schiff, 1989). Spots A, B and C represent the unknown lipids and SL indicates sulpholipid. Spot $\mathrm{C}^{\prime}$ was not included in the various analyses but may well be another taurolipid.

plastids, shows the greatest labelling in either light or darkness. Thus the presence of a proplastid in darkness lowers the labelling of compounds A, B and C and renders the cells responsive to stimulation of labelling of these compounds by light as observed in wild-type and $W_{3}$. In contrast, cells of $W_{10}$, which lack plastids, show high and fairly uniform labelling of $\mathrm{A}, \mathrm{B}$ and $\mathrm{C}$ in darkness or in light. Perhaps the plastid produces an inhibitor or repressor that blocks labelling of A, B and C in darkness, and light causes a lowering of this control molecule. As found previously (Saidha \& Schiff, 1989), labelling of the plastid thylakoid sulpholipid is stimulated by light in wild-type and in $\mathrm{W}_{3}$ (Table 1), reflecting the induction of development of the proplastid into a chloroplast in wild-type cells (Saidha \& Schiff, 1989) or limited development of the proplastid remnant in $\mathrm{W}_{3}$ (Osafune \& Schiff, 1980); $\mathrm{W}_{10}$, of course, contains no plastids (Osafune \& Schiff, 1983) and makes no sulpholipid (Table 1).

Mild acid hydrolysis releases $\left[{ }^{35} \mathrm{~S}\right]$ taurine from purified compounds A, B and C (Fig. 2). When purified (see Methods) ${ }^{35}$ S-labelled A, B and C were exposed to 2,4dinitrofluorobenzene (DNFB) (which substitutes free amino groups to yield DNP derivatives) and were then 
Table 1. Radioactivity in taurolipids (spots $A, B$ and $C$ ) and in sulpholipid $(S L)$ in dark-grown wild-type resting cells of Euglena gracilis var. bacillaris and mutants $W_{3}$ and $W_{10}$

Radioactivity was measured $48 \mathrm{~h}$ after addition of carrier-free ${ }^{35} \mathrm{SO}_{4}^{2-}$ and incubation in light or darkness. ND, Not detected.

\begin{tabular}{|c|c|c|c|c|c|c|}
\hline \multirow{3}{*}{$\begin{array}{l}\text { Lipid } \\
\text { type }\end{array}$} & \multicolumn{6}{|c|}{ Radioactivity (d.p.m. per $10^{4}$ cells) } \\
\hline & \multicolumn{2}{|c|}{ Wild-type } & \multicolumn{2}{|c|}{$\mathrm{W}_{3} \mathrm{BUL}$} & \multicolumn{2}{|c|}{$\mathrm{W}_{10} \mathrm{BSmL}$} \\
\hline & Light & Dark & Light & Dark & Light & Dark \\
\hline A & 7939 & 1520 & 5587 & 1742 & 12624 & 8636 \\
\hline B & 13825 & 3801 & 34317 & 10862 & 32998 & 32959 \\
\hline C & 32652 & 9658 & 22219 & 10303 & 41979 & 73885 \\
\hline SL & 942179 & 23379 & 103007 & 15150 & ND & ND \\
\hline
\end{tabular}

acid-hydrolysed; again, free $\left[{ }^{35} \mathrm{~S}\right]$ taurine was found on a subsequent paper electrophoresis (Fig. 3). However, if compounds A, B and C were treated with DNFB after undergoing acid hydrolysis, a labelled compound moving to the position of authentic DNP-taurine was found, indicating that the taurine is bound to the lipid in each case at least through the amino group. Unhydrolysed compound A, B or C treated with DNFB (Fig. 3) or each of the untreated compounds (not shown) stays at the origin and does not move at all. The ${ }^{35} \mathrm{~S}$-labelled acidhydrolysis products of compounds $\mathrm{A}, \mathrm{B}$ or $\mathrm{C}$ show exact co-electrophoresis with authentic taurine on electrophoresis in citrate (pH 5.8), borate ( $\mathrm{pH} \mathrm{8.0)}$ and formic/ acetic acid ( $\mathrm{pH} \mathrm{2.0)}$ buffer systems (data not shown); cochromatography in various one-dimensional or twodimensional solvent systems (see Methods) on silica gel and cellulose thin-layers was also demonstrated. Thus compounds A, B and C contain taurine that is linked, at least through the amino group, to a lipid.

Our previous work has indicated that a sulphatemetabolizing centre is present on the outside of the inner mitochondrial membrane of Euglena (Saidha et al., 1985, 1988). For this reason, it was of interest to determine whether the taurolipids of Euglena are present in the mitochondria. Fig. 4 shows that purified mitochondria from cells of Euglena $\mathrm{W}_{10} \mathrm{BSmL}$ contain the same collection of taurolipids as the whole cells. Thus, the mitochondria represent a significant depot for taurolipids in the Euglena cell. Since it is known that the loss of plastids leads to an increase in mitochondrial material in Euglena (Lefort, 1964), the increased taurolipid labelling seen in aplastidic mutant $\mathrm{W}_{10}$ compared with plastidcontaining wild-type and $\mathrm{W}_{3}$ cells (Table 1 ) is consistent with a mitochondrial site for taurolipids in Euglena.

Studies by others have demonstrated the presence of a 'taurolipid A' [identified as 2-(3-acyloxy-7,13-dihydroxyoctadecanoyl)aminoethanesulphonic acid] in Tetra-

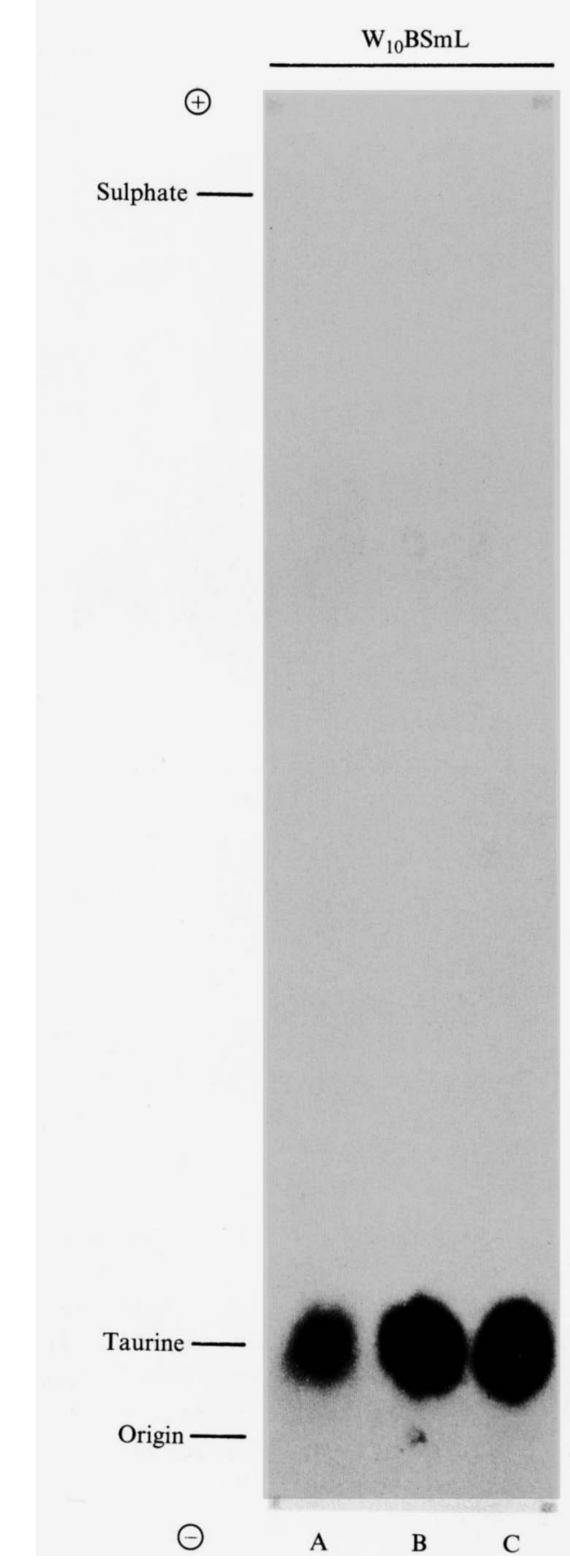

Fig. 2. Acid hydrolysis of compounds A, B and C shown in Fig. $1 .{ }^{35} \mathrm{~S}-$ Labelled compounds $\mathrm{A}, \mathrm{B}$ and $\mathrm{C}$ were isolated and purified from Euglena gracilis var. bacillaris mutant $\mathrm{W}_{10} \mathrm{BSmL}$ and were subjected to hydrolysis in $1.0 \mathrm{M}-\mathrm{HCl}$ as described in Methods. The hydrolysate was then subjected to paper electrophoresis in citrate buffer, pH 5.8. An autoradiogram of the electrophoretogram is shown; the positions of authentic sulphate and taurine are indicated for comparison.

hymena pyriformis (Kaya et al., 1985), and a 'taurolipid B' [identified as 2-(3-acyloxy-2,7,13-trihydroxyoctadecanoylaminoethanesulphonic acid] in Tetrahymena 


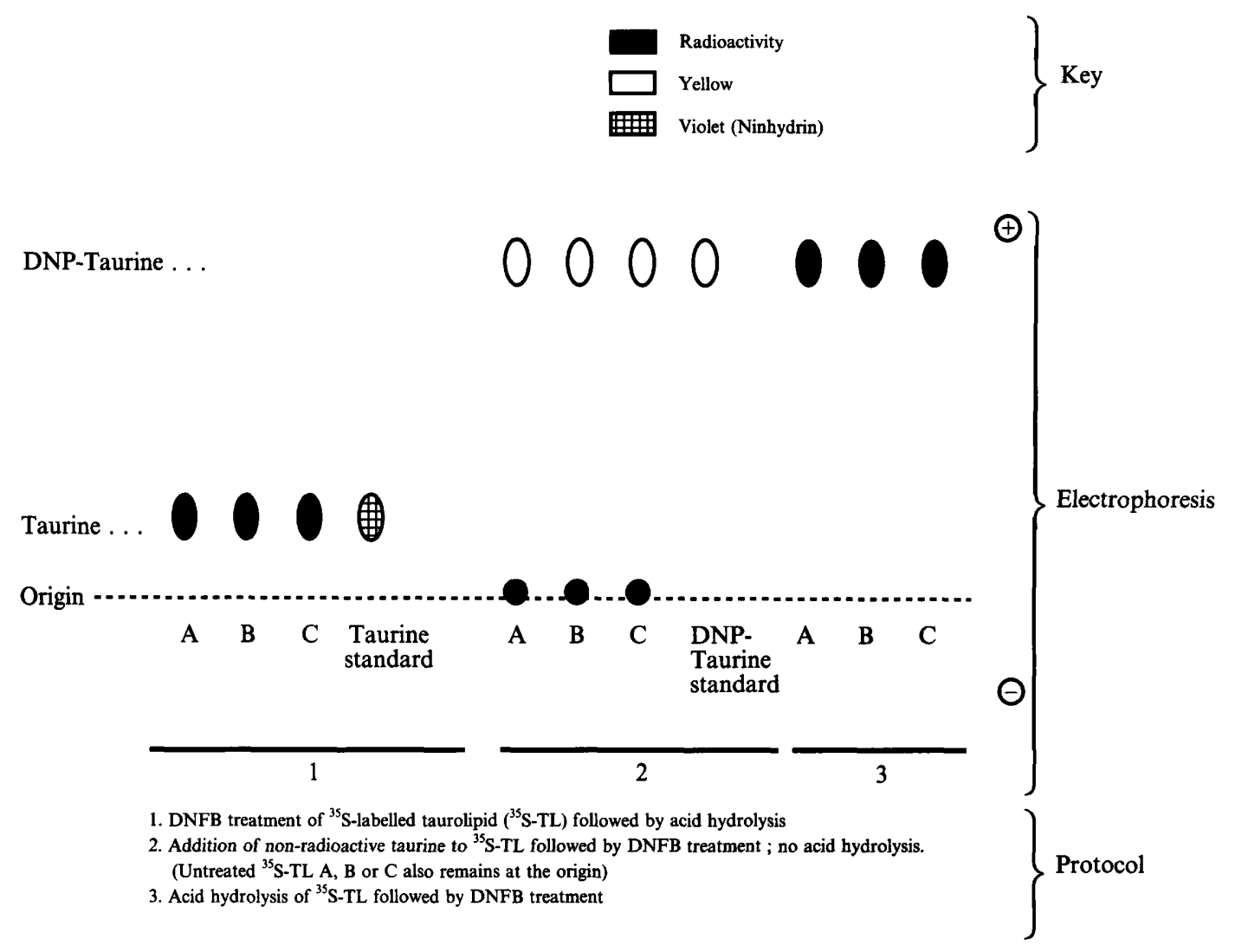

Fig. 3. Lipids A, B and C from light-grown wild-type resting cells of Euglena gracilis var. bacillaris exposed to light and ${ }^{35} \mathrm{SO}_{4}^{2-}$ for $72 \mathrm{~h}$, subjected to various treatments followed by paper electrophoresis (diagrammatic representation) in citrate buffer (pH 5.8). Upper section, key to content of electrophoresis spots; middle section, paper electrophoretogram; bottom section, protocol for treatments of lipids A, B and C preceding electrophoresis. The positions of taurine and DNP-taurine standards on the electrophoretogram are also shown.

thermophila (Kaya et al., 1986), as well as other related compounds in cells of Tetrahymena thermophila (Kaya \& Sano, 1991); the taurolipids ' $A$ ' and ' $B$ ' were shown to be present in the mitochondrial-lysosomal fraction of $T$. pyriformis and T. thermophila (Kaya \& Nohara-Uchida, 1986). The Euglena taurolipids may be quite similar to the Tetrahymena taurolipids, but this remains to be proven. (The letter designations for the various taurolipids in the two organisms were chosen independently and arbitrarily by the investigators.) Since Tetrahymena is a ciliated protozoan and Euglena is closely related to the flagellated protozoa, it is possible that similar taurolipids might be found in other protozoan groups and species. Interestingly, three other lipids are known that contain a taurine configuration [the capnoids (capnine and $\mathrm{N}$-acylcapnine) found in bacteria of the genus Capnocytophaga (Godchaux \& Leadbetter, 1980) and 1-deoxyceramide-1-sulphonic acid found in the diatom Nitzschia alba (Anderson et al., 1978, 1979)], but in these taurine is linked by carbon-carbon bonds to a long carbon skeleton.
Taurine has been implicated indirectly in the preservation of membrane integrity (e.g. Hayes et al., 1975; see Wright et al., 1986, for a review). The sulphonic acids in general (including the sulpholipid of the thylakoid membrane and the taurolipids of the mitochondria) might be very appropriate for such a function. The sulphonic acid group has a low $\mathrm{p} K$ and, therefore, is ionized at physiological $\mathrm{pH}$, is very unreactive and is very resistant to release by hydrolysis from the carbon to which it is attached. Thus as a membrane constituent, it would provide stable negative charges under a variety of conditions that might repel negatively charged deleterious chemical species such as some toxic derivatives of oxygen. The increased taurolipid formation in resting cells may represent a stress response to nutritional deprivation connected with the protection of mitochondrial membranes.

Two different forms of ATP sulphurylase are found in Euglena (Li et al., 1991); one is soluble and the other is mitochondrial. The mitochondrial enzyme is found together with the enzymes of adenosine 3'-phosphate 5'- 


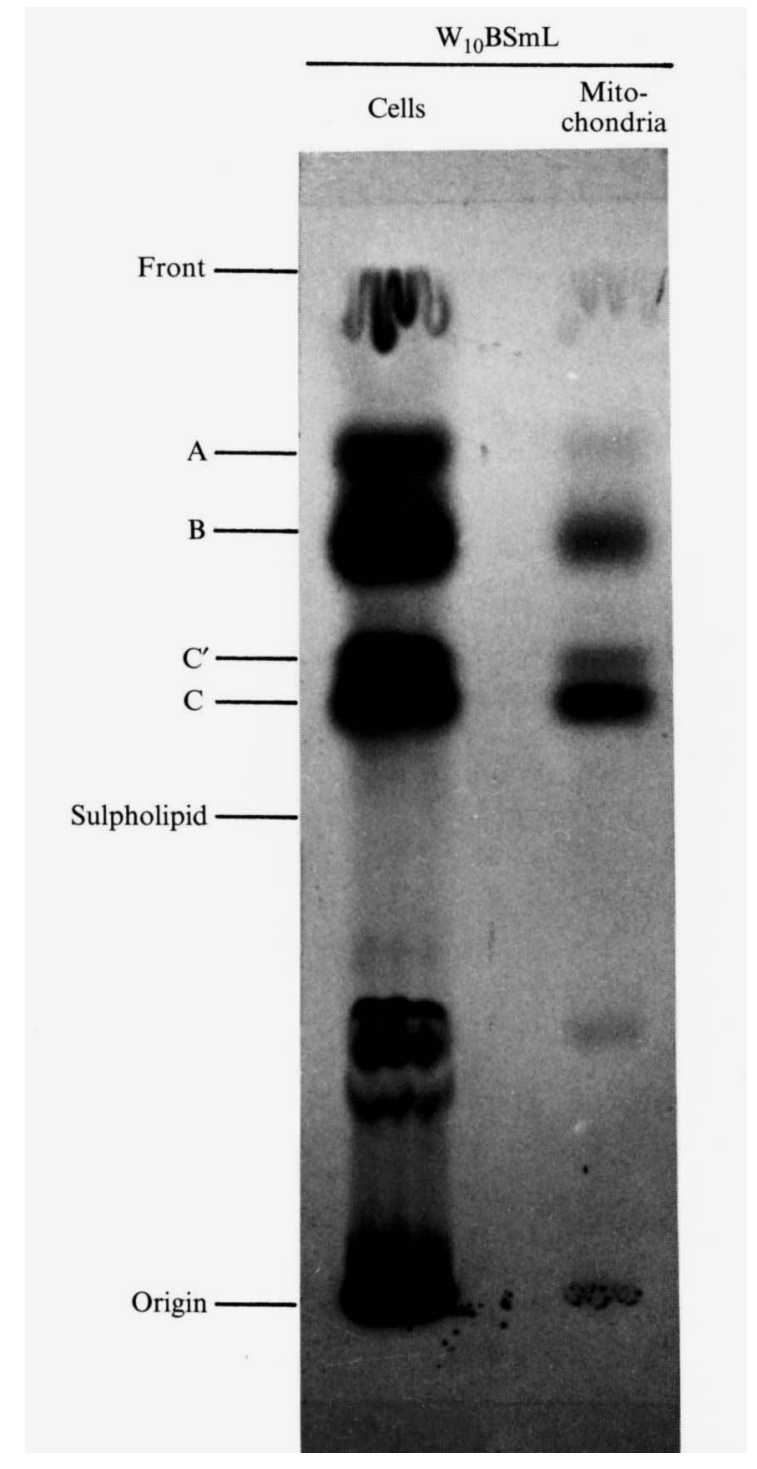

Fig. 4. Resting cells of Euglena gracilis var. bacillaris mutant $\mathrm{W}_{10} \mathrm{BSmL}$ were labelled with ${ }^{35} \mathrm{SO}_{4}^{2-}$ and mitochondria were prepared as described in Methods. Both cells and purified mitochondria were extracted with chloroform/methanol and the resulting lipid extracts were chromatographed on a silica gel thin-layer plate. An autoradiogram of the dried thin-layer plate after chromatography is shown. Note the correspondence of the major lipid spots obtained from whole cells and mitochondria.

phosphosulphate (PAPS) formation and sulphate reduction to sulphite and cysteine on the outside of the inner mitochondrial membrane (Saidha et al., 1985, 1988). The plastid receives the reduced sulphur for sulpholipid formation from the mitochondrion as sulphite or cysteine (Saidha \& Schiff, 1989); sulphite might also serve as the source of sulphur for the formation of mitochondrial taurolipids.

This work was supported by grants from the National Science Foundation. J.A.S. is the Abraham and Etta Goodman Professor of
Biology. We thank Professor K.C. Hayes for directing us to earlier literature on taurolipids. The expert technical assistance of Miss Nancy O'Donoghue is appreciated.

\section{References}

ANDERson, R., Kates, M. \& Volcani, B. E. (1978). Identification of the sulfolipids in the non-photosynthetic diatom Nitzschia alba. Biochimica et Biophysica Acta 528, 89-106.

Anderson, R., Kates, M. \& Volcani, B. E. (1979). Studies on the biosynthesis of the sulfolipids in the diatom Nitzschia alba. Biochimica et Biophysica Acta 575, 557-561.

BENSON, A. A., DANiel, H. \& Wiser, R. (1959). A sulfolipid in plants. Proceedings of the National Academy of Sciences of the United States of America 45, 1582-1587.

Cogburn, J. N. \& SCHIFF, J. A. (1984). Purification and properties of the mucus of Euglena gracilis (Euglenophyceae). Journal of Phycology 20, 533-544.

GodChaUX, W., III \& LEADBETTER, E. R. (1980). Capnocytophaga spp. contain sulfonolipids that are novel in procaryotes. Journal of Bacteriology 144, 592-602.

Gomez-Silva, B., Stern, A. I., Saidha, T. \& Schiff, J. A. (1985). Oxidative phosphorylation coupled to respiration in highly purified intact Euglena mitochondria. Journal of Plant Physiology 120, 431-440.

HaAs, R., Siebertz, H. P., Warge, K. \& Heinz, E. (1980). Localization of sulfolipid labeling within cells and chloroplasts. Planta 148, 238-244.

HaYes, K. C., Carey, R. E. \& SchmidT, S. Y. (1975). Retinal degeneration associated with taurine deficiency in the cat. Science 188, 949-951.

KAYA, K. \& Nohara-UCHIDA, K. (1986). Distribution of taurolipid in Tetrahymena cells. Biochimica et Biophysica Acta 878, 281-283.

KAYA, K. \& SANO, T. (1991). Definition of total biosynthesis pathway of taurolipids in Tetrahymena cells. Biochimica et Biophysica Acta 1084, 101-104.

KAYA, K., UCHIDA, K. \& KusUmI, T. (1985). Identification of taurinecontaining lipid in Tetrahymena pyriformis NT-1. Biochimica et Biophysica Acta 835, 77-82.

KAYA, K., UCHIDA, K. \& KUSUMI, T. (1986). Tetrahydroxystearic acidcontaining taurolipid isolated from Tetrahymena thermophila. Biochimica et Biophysica Acta 875, 97-102.

LEFORT, M. (1964). Modifications du chondriome dans les cellules étiolées de l'Euglena gracilis (Klebs). Comptes rendus de l'Académie des Sciences 258, 4318-4321.

LI, J., SAIDHA, T. \& SCHIFF, J. A. (1991). Purification and properties of two forms of ATP-sulfurylase from Euglena. Biochimica et Biophysica Acta 1078, 68-76.

Moreno-Sanchez, R. \& Raya, J. C. (1987). Preparation of coupled mitochondria from Euglena by sonication. Plant Science 48, 151-157.

OsAFUNE, T. \& SCHIFF, J. A. (1980). Events surrounding the early development of Euglena chloroplasts. 17. Light induced changes in a proplastid remnant in mutant $\mathbf{W}_{3} \mathrm{BUL}$. Journal of Ultrastructure Research 73, 64-76.

OsaFunE, T. \& SchiFf, J. A. (1983). $\mathrm{W}_{10} \mathrm{BSmL}$, a mutant of Euglena gracilis var. bacillaris lacking plastids. Experimental Cell Research 148, 530-535.

Pentz, E. I., Davenport, C. H., Glover, W. \& Smith, D. D. (1957). A test for determination of taurine in urine. Journal of Biological Chemistry 228, 433-445.

SAIDHA, T. \& SCHIF, J. A. (1989). The role of mitochondria in sulfolipid biosynthesis by Euglena chloroplasts. Biochimica et Biophysica Acta 1001, 268-273.

Saidha, T., Stern, A. I., Lee, D.-H. \& SchifF, J. A. (1985). Localization of a sulphate-activating system within Euglena mitochondria. Biochemical Journal 232, 237-365.

Saidha, T., NA, S.-Q., LI, J. \& Schiff, J. A. (1988). A sulphate metabolizing center within Euglena mitochondria. Biochemical Journal 253, 533-539.

SAIDHA, T., Stern, A. I. \& SCHIFF, J. A. (1990). Taurine conjugates in the lipid fraction of Euglena. Plant Physiology 93 (Suppl.), 145. 
SCHIFF, J. A. (1959). Studies on sulfate utilization by Chlorella pyrenoidosa using sulfate- ${ }^{35} \mathrm{~S}$; the occurrence of S-adenosyl methionine. Plant Physiology 34, 73-80.

SCHIFF, J. A. (1972). A green safelight for the study of chloroplast development and other photomorphogenetic phenomena. Methods in Enzymology 24, 321-322.

Stern, A. I., SchifF, J. A. \& Epstein, H. T. (1964). Studies of chloroplast development in Euglena. V. Pigment biosynthesis, photosynthetic oxygen evolution and carbon dioxide fixation during chloroplast development. Plant Physiology 39, 220-226.

Wright, C. E., TALLAN, H. H. \& LIN, Y. Y. (1986). Taurine: biological update. Annual Review of Biochemistry 55, 427-453.

ZELDIN, M. A. \& SCHIFF, J. A. (1967). RNA metabolism during lightinduced chloroplast development in Euglena. Plant Physiology 42, 922-932. 